\title{
EN TORNO AL FOLKLORE MUSICAL Y SU UTILIZACIÓN. EL CASO DE LAS MISIONES PEDAGÓGICAS Y LA SECCIÓN FEMENINA.*
}

\author{
Ma Asunción LIZARAZU DE MESA
}

La historia de la música está relacionada orgánica y dinámicamente con la historia de la sociedad, de la que no puede desligarse sin perder su inteligibilidad. Desde los primeros estudios de sociología de la música se observó que las funciones sociales que ésta desarrollaba estaban siempre en correspondencia con las necesidades de la sociedad, las cuales, a la larga, determinaban la forma y el estilo de las piezas musicales. Los cambios en las necesidades suponían cambios en la función y, por tanto, el surgimiento de nuevas formas, de nuevos estilos o la modificación de los antiguos ${ }^{1}$.

Los estudios sobre el cambio cultural y de cómo éste afecta a la música se han multiplicado en las últimas décadas, produciéndose análisis muy interesantes y sugerentes. John Blacking - uno de los etnomusicólogos que más se ha interesado por este tema- diferenció dos tipos de cambio: el que podía darse dentro de un mismo sistema musical y el que podía ocasionar un cambio del sistema existente por otro ${ }^{2}$.

La primera impresión que se puede tener actualmente al contemplar las transformaciones sufridas en los procesos de creación, de aprendizaje y de difusión en los que se apoyaba el sistema musical tradicional de la sociedad rural española hasta hace pocos años, es que éstas han sido radicales a causa de los movimientos migratorios y sus consecuencias sobre las estructuras

* Comunicación presentada al II Congreso de la Sociedad Ibérica de Etnomusicología. "Músicas populares y tradicionales: investigaciones en curso". Valladolid, 22 a 24 de marzo de 1996.

1. En estos términos explicó su teoría Elic Siegmeister en su obra Música y sociedad. Méjico, Siglo XXI, 1987 (2ª ed.), ( $1^{\text {a }}$ ed. en inglés, 1938). El enfoque de estudio, dentro de los postulados del funcionalismo entonces imperante - posteriormente desarrollado en diferentes sentidos- abrió nuevas perspectivas hacia la comprensión de la música como cultura.

2. John Blacking: Some problems of the theory and method in the study of musical change. Yearbook of the International Folk Music Council, vol. IX, 1977. 
sociales antiguas, así como por la difusión y popularidad de los actuales medios de comunicación. Sin embargo, un análisis detallado de la práctica musical nos revela la existencia de diferentes ritmos en el cambio —en cada fase del proceso- según los repertorios y las localidades. Esta situación no es exclusivamente contemporánea. La música de tradición oral, o de transmisión esencialmente "aural", ha vivido siempre en constante movimiento, aunque los estudios realizados en torno a ella a lo largo de este siglo hayan incidido en exceso en la cualidad de "supervivencia", de algo antiguo inalterado durante siglos. Pero como cualquier manifestación cultural, no es estática ni arcaica sino que, por estar integrada en la vida de la comunidad que la produce, por ser parte de su cultura, ha ido modificándose con ella. No únicamente "viviendo en variantes", como decía D. Ramón Menéndez Pidal del romancero, sino creando, recreando, tomando prestado, sustituyendo y olvidando temas, canciones y danzas. A finales del siglo XVI, por ejemplo, auguraba Mateo Alemán que si las seguidillas habían arrinconado a la zarabanda "otras (danzas) vendrán que las destruirán y caigan".

En el transcurso de un trabajo realizado entre 1985 y 1990 en el que estudiábamos los cambios producidos en los repertorios locales de música de tradición oral de la provincia de Guadalajara ensayamos un método de análisis que nos permitió dibujar la complejidad del proceso, aislando los elementos que intervenían en él: clase de canción, tipo de innovación ${ }^{3}$, agente innovador, intérprete y lugar de ejecución de la música así como las relaciones internas que se establecían entre cada uno de ellos ${ }^{4}$.

$\mathrm{Al}$ analizar la dinámica de estos repertorios locales se comprobó que tanto las modificaciones, como las recreaciones de melodías ajenas a la tradición cultural local, en ocasiones de autor - como conocidos cuplés- o los préstamos de canciones y melodías, se integraron en determinadas actividades y en hechos sociales a los que iban unidos mientras éstos eran revividos cíclicamente $^{5}$, unas veces sustituyendo a las piezas musicales ya existentes y otras, ampliando el cancionero local. Esto significa que la innovación, el cambio, fundamentalmente iba ocasionando una transformación lenta y gradual de estilo, pero no una alteración en el modelo de imbricarse la música con otros aspectos de la cultura. Es decir, se trataba de cambios dentro del sistema musical existente.

Si los cambios detectados - aquéllos ocurridos en el pasado de los que se guardaba memoria, una pequeña parte de los que se produjeron - pasaron a integrarse en el contexto propio de cada tipo de canción, podemos interpretar que fueron aceptados socialmente, a lo que contribuyó en gran medida el hecho de que los agentes que los producían poseían cierto prestigio

3. En este estudio hemos considerado innovación a todas aquellas novedades introducidas en cualquier tema musical o repertorio de una determinada localidad, de las que se recuerda el nombre del creador o creadores o de su introductor y/o la fecha en la que pasó a formar parte del cancionero local, aunque en los pueblos vecinos sea ya considerada tradicional por haber sido olvidados estos datos.

4. Ma Asunción Lizarazu De Mesa: Cancionero popular tradicional de la provincia de Guadalajara (3 vols.). Guadalajara, Diputación Provincial, 1996.

5. Llamamos modificaciones a variaciones en los textos o en la música dentro de la estructura de un tipo determinado de canción, generalmente improvisada al interpretarse (ejem. los cantares de ronda). Supone el grado mínimo de innovación. Los préstamos son temas musicales traídos del exterior de la comunidad. El innovador no es el creador de la canción, sino su introductor. Consideramos recreaciones a los cambios introducidos en los préstamos - consistentes en la sustitución de unos textos por otros nuevos - para adaptarlos a la nueva función que adquieren las canciones. 
social, bien porque pertenecían a instituciones prestigiosas ligadas a la enseñanza institucionalizada de una forma oficial: la Iglesia y la escuela, bien porque se trataba de personas a las que se les reconocía una mayor cultura académica o un gran conocimiento de la cultura local (copleros o especialistas locales).

Aunque no de forma estricta, parece que existe una cierta asociación entre el tipo de agente que introduce el cambio y el tipo de cambio que se produce. Mientras que lo que denominamos modificaciones - la mayoría de las improvisaciones - aparecían con más frecuencia en canciones profanas ligadas al cancionero masculino, la mayor parte de los préstamos se producían en el repertorio femenino, tanto de casadas como de mozas y niñas, es decir, en los repertorios de los grupos sociales con mayor contacto con la Iglesia y la escuela. Las recreaciones, por su parte, escasamente representadas y con frecuencia integradas en fiestas locales recuperadas o en el culto a la Virgen, eran debidas a compositores esporádicos, tanto de procedencia local como forasteros.

Es significativo el período de tiempo durante el que se produjeron gran parte de los préstamos y recreaciones documentadas, pues además de indicarnos una fase en la que el repertorio que estudiamos se hallaba en plena vigencia, deja traslucir corrientes más amplias, modas, políticas culturales y educativas de ámbito nacional, ideologías, etc.... Así, varias de las canciones escolares recogidas fueron aprendidas entre los años veinte y la instauración de la Segunda República, años en los que la escuela española recibe un impulso desde el Estado y comienza a mostrar indicios de renovación. También los cuplés, a los que se les cambia el texto, fueron introducidos en estas fechas. Aisladamente penetraron canciones a través de los soldados durante la guerra civil, de las maestras durante la postguerra o de personas que en un momento dado llegan al pueblo. El recuerdo de la introducción de nuevas canciones religiosas se retrotraía hasta principios del siglo, pero fundamentalmente se centraba en los comienzos de los años anteriores a la República y en los posteriores a la Guerra Civil, sobre todo en los años cuarenta y primer quinquenio de los cincuenta, el período más fuerte đel nacional-catolicismo. Son interesantes también las modificaciones aplicadas al mayo de Alcoroches para presentarlo en un concurso folklórico de televisión en los años 60, época de despegue de éste medio de comunicación y de auge de los Coros y Danzas.

Estos datos dejaban entrever cierta influencia -en las personas y en la música que interpretaban - de las políticas culturales de diferentes momentos de este siglo llevadas a cabo por organizaciones directa o indirectamente vinculadas al Estado, como las Misiones Pedagógicas y la Sección Femenina, que utilizaron la música popular tradicional como vehículo educativo y de transmisión de ideología - es decir, de ideas convertidas en sistema de pensamiento, en doctrina o dogma- Pero llamaba la atención el que los efectos de las actividades ejercidas durante años - décadas, en el caso de la Sección Femenina- no se revelaban muy importantes. Esto en parte se debía, sin duda, al planteamiento metodológico desarrollado en el trabajo del que hablamos, pero también a otras causas que ahora intentamos examinar.

El estudio, actualmente en proceso, se ha iniciado con el análisis de los documentos de archivo: programas de actuación, discursos, informes de trabajo, bibliografía, etc... que, de un lado proporcionan el marco teórico político, social, educativo que puso en marcha a dichas 
organizaciones, y de otro, su metodología de trabajo, su organización e infraestructuras ${ }^{6}$. Esta programática oficial se ha completado con entrevistas a las personas que participaron en dichos programas, como organizadoras o como ejecutoras de los mismos, en el ámbito geográfico que estamos estudiando: la provincia de Guadalajara. La documentación consultada hasta hoy nos ha permitido aproximarnos a los móviles que llevaron a utilizar la música popular tradicional en determinados sentidos y los resultados que obtuvieron. Como veremos, la función que cumplió la música y el uso que hicieron de ella las Misiones Pedagógicas y la Sección Femenina ha sido muy diferente en el planteamiento, en la realización de los programas y en el período de tiempo que cada una de las organizaciones contó para su desarrollo.

\title{
Las Misiones Pedagógicas
}

Nacen del Museo Pedagógico creado por D. Manuel Bartolomé Cossío en la línea de la Institución Libre de Enseñanza. La finalidad que persiguen se especifica en la Constitución de su Patronato que dice: "se trata de llevar a las gentes el aliento del progreso y los medios de participar en él, en sus estímulos morales".

En la presentación de los informes de 1931 a 1933 se explica que el aislamiento de los pueblos y la justicia social están en el origen de las Misiones cuyo objetivo es: "la comunicación para enriquecer las almas y hacer que vaya surgiendo en ellas un pequeño mundo de ideas y de intereses, de relaciones humanas y divinas que antes no existían"”. Pero su propósito difiere del de las escuelas porque como el mismo documento declara:

\begin{abstract}
"Tal vez la menor cantidad de nuestro saber, y no hay que decir nada de nuestro mundo afectivo, con el que al par de la ciencia se enriquece el espíritu, nos viene a todos de las aulas, fuera de las cuales, en forma espontánea y difusa, hemos ido atesorando en cada momento, día tras día, sin saberlo, de un modo libre y ocasional, en libros, periódicos, conversaciones, trato familiar y amistoso, en el comercio humano con espíritus superiores, en los espectáculos, en los viajes, en la calle, en el campo... el enorme caudal de cultura con que insensiblemente engalanamos la vida. Y este ambiente antiprofesional, irreflexivo, libre y difuso, donde aprendemos, al parecer sin pagar nada, todo aquello que alguien con castizo gracejo llamaba 'aprendido de gorra', debe ser justamente el campo que constituya como unidad el contenido esencial de la acción misionera"
\end{abstract}

Se trataba, pues, de suscitar en los pueblos una visión siquiera tenue de lo que otros en las ciudades podían disfrutar, sin que hubiera ninguna preocupación de formación profesional, sino todo lo contrario, primando lo lúdico. Mediante la enseñanza de las características de su entorno geográfico, la valoración de sus canciones, su literatura y su música originales, se buscaba pie para nuevos conocimientos. Para ello se organizaron servicios de música, de biblioteca, de

6. En el caso de las Misiones Pedagógicas se han analizado los informes correspondientes a los años 1931 a 1933 publicados por $\mathrm{M}^{\mathrm{a}}$ Dolores CABra Loredo (ed.): Misiones Pedagógicas. Informes I: Septiembre de 1931-Diciembre de 1933. Madrid, El Museo Universal, 1992. Una aproximación a la historia de la Sección Femenina que me ha resultado muy valiosa es el trabajo de Luis SuÁrez Fernández: Crónica y Guía de la Sección Femenina y su tiempo. Madrid, Nueva Andadura, 1992.

7. Cabra Loredo, $\mathrm{M}^{\mathrm{a}} \mathrm{D}$. (ed.): op. cit., pág. X.

8. Ibídem, pág. XI. 
cine y proyecciones fijas, de coro y teatro y un museo circulante. Se dirigían a todo el mundo, hombres y mujeres, jóvenes y adultos. Estudiantes de distintos cursos y maestros eran los principales colaboradores de la Misión que convivía con los aldeanos varios días en cada pueblo, pocos, donde era introducida por el maestro local, al cuidado del cual dejaban al marchar libros y discos.

El servicio de música se componía de un Coro de Misiones, unido al teatro popular, integrado por estudiantes que interpretaban canciones y romances populares. También disponía de discos de música desde Bach a Stravinski y de autores españoles como Chapí, Bretón, Albéniz, Falla, Esplá, Turina y García Lorca; de canto gregoriano y de canciones regionales: gallegas, asturianas, montañesas, catalanas, valencianas, andaluzas, castellanas... y de 38 gramófonos confiados a maestros nacionales y a otras personas en las localidades más apartadas.

Las sesiones de música, tanto las dirigidas a niños como las de adultos consistían en una audición acompañada de su comentario. El coro, junto con el teatro del pueblo, hacía salidas todos los domingos y en vacaciones. Llevaba un repertorio musical, fundido con frecuencia con el escénico, de canciones tradicionales recogidas en distintas provincias y romances: canciones castellanas de ronda, de boda, de baile, romances como la Loba Parda, el Conde Olinos o la Doncella Guerrera cuyos textos, a veces con la notación musical incluida, eran repartidos en copias entre el público después de cada representación para que pudieran ser leídos en corrillos.

Son muy interesantes los comentarios que aparecen en los informes que se realizan al finalizar cada misión sobre las reacciones que ha causado la visita en el pueblo. Después de los tres primeros años de Misiones, el servicio de música reconoce que:

\footnotetext{
“...no sería discreto aventurar aún apreciaciones fundadas a cerca del influjo que pueda atribuirse a esta modestísima labor musical entre gentes que sólo conocen los propios cantos, arrinconados hoy por el cuplé y otras estridencias agresivas de la ciudad. Ni debe extrañarnos que el pueblo del campo conceda marcada y unánime preferencia a la lírica regional y no encuentre siempre complacencia en la música que suele recrear el oído cultivado. La obra educadora, sobre todo si se aspira a la relación con la pura belleza, lo es del tiempo y del influjo continuado, que en este caso el Patronato habrá de favorecer, mientras puede hacerlo" ${ }^{\text {. }}$.
}

Que la música no es siempre un lenguaje universal lo prueba no sólo el hecho de que la música clásica europea les aburriera y les ahuyentase de las audiciones en la gran mayoría de los casos - y a este respecto hay que señalar la excepción del pueblo soriano de Alcubilla de Avellaneda donde esta música, excepto las sinfonías alemanas, sí despertaron entusiasmo-, sino también el que entre los cantos regionales prefiriesen los más próximos a su zona, llegando a provocar autentica risa los de provincias más alejadas, como comentan en el informe de la misión de Castropol (Asturias) respecto a una de las canciones favoritas de Bonansa (Huesca).

La poesía, tanto la lírica tradicional como la nueva, igualmente alcanza un éxito sorprendente según comentan los misioneros. En el detallado informe de Valdepeñas de la Sierra, en la provincia de Guadalajara, se observa que "de la poesía prefieren la lírica a la narrativa, y de los

9. Ibídem, pág. 73. 
romances los de sabor villanesco a los heroicos y maravillosos. De la música prefieren la voz humana a la instrumental" y, entre la música de autor, disfrutan con la zarzuela ${ }^{10}$.

Las Misiones tuvieron una diferente acogida según los pueblos. En gran parte de ellos, los informes reflejan la actitud de sorpresa, alegría y gratitud que causaba su estancia al ver que la Nación o el Gobierno - como solían decir en las aldeas- se acordaba por fin de ellos. Pero también existían recelos. En el informe de Puebla de Beleña (Guadalajara), pequeña localidad con estación de ferrocarril, lugar de veraneo y con relaciones más directas con la capital de la provincia y Madrid, la Misión se lamenta de haber sido acogida "con recelo cazurro, cohibido y malicioso al mismo tiempo; sospecharon quizá de una propaganda política y se disponían a valorar su voto"11.

Las Misiones que recorrieron Guadalajara fueron dos. Una, centrada en Valdepeñas de la Sierra (18 a 25 de febrero de 1932), desde donde se desplazaba a pueblos cercanos: Alpedrete, Puebla de Beleña, La Mierla y Tamajón en visitas de un día. Y otra abarcó la serranía de Atienza (del 24 de mayo al 1 de junio de 1933), recorriendo Condemios de Abajo, Galve de Sorbe, Cantalojas, Valverde de los Arroyos, Campillo de Ranas y Colmenar de la Sierra. En ambas participaron el Servicio de Música y el de Cine y Proyecciones fijas. El teatro y el coro actuaron en pueblos de la comarca de la Campiña, próximos a Madrid, durante 1933 y el Museo, que sólo acudía a los pueblos más grandes, estuvo el mismo año en Cifuentes y Atienza. El período electoral y la intranquilidad del país obligaron a espaciar los viajes cada vez más en el otoño de 1933.

\section{La Sección Femenina}

Surge como la rama femenina de la Falange, con un fuerte contenido político, y a la consecución de los fines propugnados por esta ideología dirigió todos sus esfuerzos. Aunque pronto se integró en el Movimiento franquista, siempre fue fiel al pensamiento joseantoniano.

Las tres bases sobre las que se asienta se establecen en los estatutos de 1937:

- Es nacional. España, para José Antonio "es varia y plural, pero sus pueblos varios, con sus lenguas, con sus características, están unidos irrevocablemente en una unidad de destino en lo universal".

- Es católica y la interpretación católica de la vida es la verdadera.

- Se orienta hacia la justicia social.

Ya en el congreso nacional de 1939 (el III), en el que se plantea una organización de la Sección Femenina más estructurada de la que hasta entonces había tenido, se ve la música como un medio de conseguir la unidad de España. En las conclusiones del congreso se dice:

10. Ibídem, pág 31 .

11. Ibídem, pág. 33. 
"La unidad se consigue en gran parte por estas tres cosas: la doctrina nacional-sindicalista; la música (el día en que los cantos de las distintas regiones se conozcan e interpreten por todos, ayudándose así en la recíproca comprensión) y la tierra"12.

Al año siguiente se puso en marcha la idea de "rescatar" el folklore regional español y para celebrar el primer año de la "Victoria" se dispuso que "las muchachas de la S.F. cantasen y bailasen en las plazas de sus pueblos, como sus abuelos, usando además en sus canciones la lengua originaria de las mismas"

La concepción de la música como símbolo de la unidad nacional es constante. Así lo vuelve a repetir Pilar Primo de Rivera en 1942:

"Cuando los catalanes sepan cantar las canciones de Castilla, cuando en Castilla se conozcan también las sardanas y sepan tocar el txistu, cuando el cante andaluz enseñe toda su profundidad y toda su filosofía que tiene, cuando las canciones de Galicia se conozcan en Levante, cuando se unan cincuenta o sesenta mil voces para cantar una misma canción, entonces sí habremos conseguido la unidad entre los hombres y tierras de España" ${ }^{14}$.

Este "rescate" debía efectuarse desde tres ejes fundamentales. Ante todo se trataba de restaurar y salvar de su extinción formas populares muy radicales en el ser de España, símbolos de identificación nacional. Al mismo tiempo se incorporó el baile a los programas de educación física, como expresión tanto de la feminidad como de la masculinidad. La educación física se consideró una actividad fundamental para educar el cuerpo y el espíritu de la juventud. Por último se decidió introducir el espíritu de la competición a través de concursos provinciales, regionales y nacionales para incentivar la creación y mantenimiento de grupos (en 1942 actuaron ya 350 coros y su número, tanto de coros como de grupos de danza, fue creciendo rápidamente).

La formación de la mujer, no sólo del campo sino también de la ciudad, fue una de sus prioridades y en esta formación la Música jugó un importante papel siendo, junto con la doctrina del nacional-sindicalismo y la religión, asignatura obligada en los cuatro tipos de escuelas que la Sección Femenina puso en marcha: Escuelas de Hogar y Música —dirigidas a la educación de maestras que tuvieran que impartir estas materias en los distintos niveles de educación escolar-, Escuelas de Orientación Rural, Escuelas de Educación Física y Escuelas Nocturnas — también llamadas de formación, dirigidas a desarraigar el analfabetismo-. A estas escuelas se añadieron desde 1946 las Cátedras Ambulantes "Francisco Franco" con la intención de llegar a todos los pueblos y aldeas, en los que podían permanecer de uno a tres meses y, ya en la década de los sesenta, las Cátedras “José Antonio", ubicadas en los grupos de viviendas de protección oficial construidas para combatir el chabolismo y creadas con el fin de conseguir "la elevación del nivel cultural general y de la vida de la familia completa y la orientación e iniciación profesional a la misma para futuras actividades en la Cátedra Permanente y futuro Centro Social" ${ }^{15}$. En este sentido preparaban para la obtención del certificado de estudios primarios o para la realización

12. SuÁREZ FERnÁNDEZ, L.: op. cit., pág. 96.

13. Ibídem, pág. 125.

14. Ibídem, pág. 239.

15. Sección Femenina: Cátedras "José Antonio". Planificación. Madrid, enero, 1965. 
de trabajos que serían comercializados después por la Empresa Nacional de Artesanía, al mismo tiempo que creaban teleclubes e iniciaban bibliotecas, discotecas, equipos de deportes o grupos de música y danza. Pronto se hicieron cargo de las clases de Política y de Enseñanzas del Hogar -entre las que se contemplaba la música, que fue incluida en los planes de estudio de bachillerato en 1954- de todos los colegios e institutos de enseñanza secundaria, así como de vigilar el cumplimiento del Servicio Social, obligatorio para todas la mujeres que quisieran incorporarse a un puesto de trabajo, con lo que un amplio ámbito educativo de la mujer quedaba bajo su control y responsabilidad.

La cátedra ambulante de la provincia de Guadalajara fue la primera en ponerse en marcha, recorriendo a lo largo de los años un gran número de localidades. Estaba integrada por una jefa de cátedra; una médico puericultora, enfermera o divulgadora rural; una instructora rural; una profesora de corte y confección; otra de labores y trabajos manuales y finalmente una instructora de juventudes, encargada de la formación religiosa, político-social y de la gimnasia. Con ellas colaboraban autoridades locales, religiosas, el maestro o maestra del pueblo e instituciones como Sindicatos-P.P.O. y la Cámara Agraria.

Entre las actividades que desarrollaba la instructora de juventud — distintas según se dirigieran a hombres, mujeres o mozas y según las características de cada pueblo-, el re glamento establecía la de dar clases de canciones y bailes regionales tanto a niñas como a adultos y grupos mixtos, siempre que fueran de su propia región - lo cual, aunque parece estar en contradicción con la primera idea expresada por la Fundadora, pretendía evitar el confusionismo y la contaminación del folklore musical local_-, si bien en la práctica las instructoras enseñaban un repertorio más extenso, del que debían dar información sobre su procedencia geográfica al alumnado. Para las juventudes se recomendaba principalmente las canciones de corro y romances; para las mozas, enseñar con mayor insistencia las de religión. Se daba también la siguiente consigna: "Debéis procurar sacar el folklore de los pueblos por donde paséis y ponerlo en conocimiento del departamento provincial, para que a su vez lo pase a la Regidora Central de Cultura"16.

Ya en 1938 se organizó el Primer Curso Nacional de Música en el que se formaron la primeras Instructoras que, entre otras tareas, debían recoger y divulgar la música popular. Pero estos cursos no debieron ser suficientes, como se deduce de algunas manifestaciones de la Regidora de Cultura acerca de la dificultad de realizar el trabajo careciendo de personas sin la suficiente preparación técnica, aunque desde Madrid se mandaban instrucciones para llevarlo a cabo y coordinar lo realizado en todas las provincias. Se elaboró un cuestionario muy básico, que debían contestar en todos los pueblos donde fueran las cátedras, y que servía de base para el desarrollo de la recopilación. Las preguntas eran las siguientes:

1.- ¿Cómo es el traje característico del pueblo?

2.- ¿Cuáles son las canciones regionales que más cantan?

3.- ¿Qué danzas populares bailan en las fiestas patronales?

4.- ¿Qué instrumentos utilizan en las danzas?, ¿Hay alguno típico del pueblo?

16. Ibídem. 
5.- ¿Qué fiestas patronales celebran y en qué fechas?

6.- ¿Hay alguna costumbre religiosa o popular que sigan en el pueblo, o recuerda alguien en el pueblo alguna costumbre?

Al terminar la cátedra, la profesora de Hogar debía enviar un informe formalizado al Servicio Central de Cátedras en el que se reflejaba el número de clases impartidas —entre las que se especificaba las de canciones y danzas-, el de asistentes a los cursos, a las charlas, al servicio de biblioteca y los concursos y exposiciones realizadas. En este impreso se reservaba un apartado que hacía referencia a la recogida de folklore, tradiciones y costumbres (número de danzas, canciones, trajes, recetas de cocina y repostería, bordados, costumbres, etc. recopilados). Los datos de cada traje, danza o canción recopilada debían remitirse en una ficha-informe individual, de cartulina, que pasaba a formar parte del catálogo que se fue elaborando a nivel nacional.

En las fichas se anotaba información sobre el lugar y fecha de la recopilación, historial de la pieza y fuente de la información; tema — cuando se trataba de una canción- o coreografía, traje de danza, música - ritmo y texto- e instrumentos y número de danzantes, en el caso de una danza, así como datos someros del contexto habitual de ejecución y sobre la forma en que había sido dada a conocer por la Sección Femenina - concurso de coros o danzas, modificaciones introducidas en las canciones del tipo de armonizaciones para distintas voces o variaciones en las prendas del traje popular, etc- La calidad de los datos de cada ficha es, como se puede suponer, muy variable, siempre en relación con la formación de la persona que la escribió.

Las danzas también fueron recogidas por las instructoras de Educación Física quienes, como hemos dicho, debían incluir en sus programas educativos una parte dedicada a los bailes regionales. De dos en dos recorrieron las localidades donde tenían noticia de que se ejecutaban danzas, permaneciendo en ellas el tiempo necesario para llegar a bailarlas, alojadas en casas vacías cedidas por el pueblo, que con frecuencia ellas mismas acondicionaban.

Por mediación de las autoridades locales reunían a sus "informantes" al atardecer - después del trabajo en el campo-, en alguna sala amplia del lugar, si era posible. La mayoría de los reunidos - al menos en la zona que tratamos- eran hombres y mujeres entre 60 y 70 años que, según las instructoras, conocían bailes que en ese momento ya casi no se ejecutaban. Éstas, sin un sistema de notación concreto, repetían los pasos y las mudanzas con los danzantes hasta conseguir aprenderlas, a pesar del poco entusiasmo que parece que mostraban las gentes para colaborar en la enseñanza de su folklore. En algunas localidades incluso se negaron rotundamente a mostrarlas, cuando se trataba de danzas vinculadas a una cofradía y ejecutadas en una festividad concreta - caso de Valverde de los Arroyos-. Las cofradías eran muy celosas en la conservación y "apropiación" de su patrimonio.

Las danzas recogidas en los pueblos eran enseñadas por las instructoras a grupos formados en las ciudades o pueblos grandes en los que había alguna escuela de S.F., compuestos en su mayoría por personas pertenecientes a la Falange o procedentes de los centros en los que impartían sus clases. Estos grupos competían en los concursos provinciales, regionales y nacionales, ataviados con los trajes que se habían documentado al mismo tiempo que las danzas en las diferentes zonas. 
En los concursos se valoraba la originalidad en el baile - esto es, si se presentaba por primera vez en un concurso y si no estaba publicado-; la autenticidad en la interpretación; la interpretación misma; los trajes; la rondalla; el cantador y el coro y las entradas y salidas a escena.

Esta labor de recopilación se llevó a cabo bajo el asesoramiento de importantes musicólogos dando lugar a la publicación de cancioneros y libros de danzas - los realizados por Manuel García Matos, por ejemplo, en Castilla-La Mancha, Extremadura o Andalucía- que se utilizaron en las enseñanzas musicales de las escuelas e institutos de bachillerato. Se realizaron abundantes grabaciones sonoras y cinematográficas, fundamentalmente a través de NO-DO, documentales de gran interés sociológico en la actualidad. En 1969 la Fundación Juan March subvencionó una película en color de todos los bailes. Hubo concursos para recoger material y en 1973 se solicitó de nuevo la ayuda de la misma Fundación para crear un archivo Nacional de Canciones, Danzas y Trajes de España.

Pero además de la recopilación y las publicaciones, las exhibiciones de Coros y Danzas fueron unas de las imágenes más difundidas de una época, de una institución e, incluso, del país. En el interior, participaban en la mayoría de las fiestas oficiales o culturales, tanto nacionales como locales o regionales. En 1948 comienzan a salir al exterior para participar en concursos folklóricos internacionales y también como misiones diplomáticas, en unos momentos de difíciles relaciones exteriores a causa del bloqueo internacional. Éstas se dirigieron primero a diversos países de Hispanoamérica donde, a pesar de la incertidumbre de los preparativos del viaje y de algunos conflictos con exiliados, los resultados son considerados positivos desde el punto de vista político y social y allí regresaron en otras ocasiones. Posteriormente, los Coros y Danzas son utilizados como vehículos de buena voluntad en viajes a Grecia y Próximo Oriente, zonas de gran interés para España. En este caso, en el informe que la Regidora de Cultura remitió a Pilar rimo de Rivera se decía que los resultados políticos habían sido nulos, pero que el entusiasmo de la colonia sefardí compensaba todos los esfuerzos ${ }^{17}$. Sin embargo, el resultado global de los primeros años de viajes según los embajadores - también lo refleja la prensa- era excelente desde el punto de vista de la política exterior pues proporcionaba una imagen amable de España.

Las actuaciones por Europa y en Estados Unidos se realizaron a través de contratos con empresarios, lo que ponía de manifiesto que era un espectáculo cotizable — uno de los aspectos más rentables de la S.F.- pero sin embargo, en los primeros viajes a París, Bélgica o Italia se produjeron incidentes, con manifestaciones de estudiantes y exiliados en contra del régimen político que representaban los Coros y Danzas. También realizaron giras por España. En 1972 se celebró el último concurso nacional, el XIX, en el que se presentaron 17 bailes y 36 canciones inéditas. En la significativa fecha del 1 de Abril de 1977 la Sección Femenina fue suprimida por decreto.

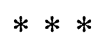

17. Citado por L. SuÁrez Fernández, op. cit. pág. 229.

[10] 
La utilización de la música en los dos casos vistos difiere radicalmente en el planteamiento, si bien se puede apreciar en ambos una concepción del folklore derivada del romanticismo, entendido como verdadera esencia del pueblo. Un pueblo al que se le percibe más auténtico cuanto más campesino y alejado de la ciudad, pero que, por esta misma razón es "inculto" y al que, desde los planteamientos de la élite intelectual urbana, hay que cultivar. Esto significa transmitirle algunos conocimientos que le permitan integrarse en las nuevas realidades de cada momento. Aquéllos que, según las concepciones ideológicas de los Estados y de las organizaciones que de él dependen - como ocurre en todos los tiempos—, son los más adecuados, también, para la formación de las personas y de las colectividades en determinados valores. Paradójicamente, esta labor lleva consigo el abandono o la alteración de muchos saberes considerados tradicionales y "puros" y es por ello que se hace necesaria la tarea de valorarlos y recopilarlos. En esta línea de interpretación, el folklore puede adquirir, además, un valor de identidad nacional con connotaciones morales, valor que fue utilizado constantemente por la Sección Femenina con el apoyo de muchos intelectuales de la época ${ }^{18}$, retomando las teorías de la "Volkskunde" germánica del siglo diecinueve.

Ambas organizaciones realizaron una labor divulgadora y una labor formativa, a las que añadió la Sección Femenina la de recopilación. Como divulgadores, se encontraron con un desinterés generalizado por los conocimientos concretos que se querían transmitir, según reflejan los informes. De las Misiones - a quienes confundían con los "cómicos" en algunas aldeas-, lo que realmente fascinaba no era la Gran Cultura que mostraban: la Gran Música o los Grandes Pintores españoles y europeos, sino aquellos "artilugios", antes nunca vistos, que giraban y emitían sonidos - no los sonidos mismos - o aquellos otros que proyectaban una luz sobre una pared, en la que se apreciaba gentes moviéndose que podían ser, con sorpresa para ellos, los propios espectadores anteriormente filmados. Tampoco interesaba mucho la formación política nacional-sindicalista, ni la religión, ni las charlas culturales, ni siquiera las canciones regionales, alejadas como estaban todas estas materias de las actividades cotidianas de las alumnas de la Sección Femenina. Son los cursos de corte y confección y algunos de artesanía los que alcanzan

18. Sobre la moral que transmite el folklore escribía J. M ${ }^{a}$ PEMÁN en ABC en 1956, a propósito de una encuesta sobre los valores de los jóvenes del momento, una alabanza a las danzas interpretadas por los Coros y Danzas de Sección Femenina por considerarlas un regreso a la vitalidad hispánica frente a los "héroes demenciales" del Rock and Roll o los "héroes tristes" de los blues y los boogies que entusiasmaban a los jóvenes americanos o las enseñanzas nihilistas de Sartre y Sagan seguidas por los franceses.

Los artículos aparecidos en prensa que inciden en este sentido son constantes. Valga como ejemplo el aparecido en "La Vanguardia" el 20 de junio de 1956 firmado por Antonio FERNÁnDEZ-Cid titulado "La Sección Femenina y las danzas populares de España":

“... En sus concursos, en sus exhibiciones aquende y allende fronteras, han florecido muestras múltiples de las más tradicionales, conmovedoras, admirables músicas y danzas de España, con un sello de autenticidad irrebatible, con la gracia de lo espontáneo, lo que no se adultera por el menor elemento extraño, lo que conserva toda su prístina hermosura, su grandeza espiritual, su gracia fresca y su carácter, su tipismo, su acento peculiar."

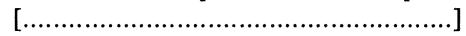

"En cada concurso, unas ( $\mathrm{sic}$ ) cientos de actuantes que representan miles tan meritorias como ellas mismas, y ante nuestro éxtasis, airosos paseos de 'muñeira', muelle sensualismo de Mallorca, gracia luminosa de la sevillana, precisión geométrica de la 'espatadantza', polícromo acento de la 'folía' canaria, trenzado puro del bolero castellano, ascético cuadro de máximo arcaísmo en cualquier rincón perdido de nuestra geografía, leves pasos que hallan el mayor contraste en los rudos, penetrantes sones de la cobla en los bailes catalanes, viril acento de la jota aragonesa..." 
el éxito más extendido entre los impartidos por las cátedras ambulantes, por su fácil y útil aplicación directa a la vida diaria (aunque esta apreciación varió de los primeros años de vida de las cátedras a los últimos).

Como consecuencia de cada uno de los planteamientos iniciales, la diferencia de método en la ejecución de los objetivos es notable. Uno, el de las Misiones, informal, basado en el disfrute y el fomento de la sensibilidad como camino para poder apreciar otras perspectivas culturales. Otro, el de la Sección Femenina, organizado a través de una enseñanza disciplinada y reglamentada hasta en sus más mínimos detalles, con una orientación ideológica claramente establecida, empeñada en crear un "estilo y modo de ser" falangista. La labor divulgadora de las cátedras, si bien duró décadas, se basó en estancias cortas en los pueblos, al igual que hicieron las Misiones. Pero esta acción esporádica se vio reforzada —en el primer caso- con otros instrumentos de difusión cultural participativos como los concursos anuales de villancicos, los de coros y danzas $\mathrm{y}$, en menor medida, por los discos y los libros editados en estos años y que quedaron en los pueblos, con toda probabilidad, abandonados paulatinamente.

La influencia mayor se ejerció de una forma indirecta, a través de la formación de formadores - las maestras y los maestros-, tarea que preocupó desde el principio a la Sección Femenina, consciente de su importancia. Al ser las personas que permanecían en los pueblos y aldeas períodos más largos, practicando su trabajo docente diariamente, en ocasiones con varias generaciones de niños y niñas del mismo lugar, fueron las que mejor contribuyeron a la consolidación de un ambiente cultural, político y social del que ellas mismas son también un producto y que se trasluce en el aspecto musical. Las maestras principalmente, pero también los maestros, conocen los programas que tienen que transmitir, se ajustan a una discografía — cuando disponen de ella- y a una bibliografía. Ésta se fija en los programas oficiales de enscñanzas del hogar - sólo para niñas - entre las que se contempla la música y con ella el aprendizaje de unos himnos y unas canciones populares especificadas, a partir de los años cuarenta. Los cambios e innovaciones más significativas aparecidas en los repertorios musicales interpretados por niñas en las localidades estudiadas de la provincia de Guadalajara se deben a esta acción docente. En menor medida la actividad de las maestras también intervino en el repertorio religioso de las mujeres, componiendo textos para himnos, rogativas y enseñando canciones dedicadas a la Virgen María, pues realizaron con frecuencia una labor de catequesis tanto dentro como fuera de la escuela dependiendo de la predisposición personal de cada una de ellas. En los otros repertorios la incidencia de la labor de las dos organizaciones de las que estamos tratando fue mucho menor $\mathrm{y}$, aunque los intérpretes locales aprendieran cantos populares de distinta procedencia, pocos pasaron a ser considerados propios y a integrarse en los hechos musicales de cada lugar, quizá a causa del desmantelamiento que estaba sufriendo al mismo tiempo la sociedad rural. La alteración se produjo en aquellos repertorios y temas coincidentes - existentes en la localidad o potencialmente aplicables a algún ritual o actividad y los utilizados en la docencia, como podían ser los romances, las canciones de juegos o determinados cantos religiosos- ya que no se trataba tanto de intervenir en los repertorios como de recopilar, seleccionar y depurar una parte del folklore con los fines declarados en cada caso (educación, valores morales, identidad nacional, etc.). 
El peso que tuvo la labor recopiladora de S.F. en la persistencia de las danzas locales vino motivado por el interés que mostró hacia ese patrimonio. Es curioso señalar que las danzas de la provincia de Guadalajara vigentes en su contexto tradicional actualmente, con carácter ritual, vinculadas a festividades religiosas, fueron recopiladas por la Sección Femenina ${ }^{19}$, pero no hay que dejar de tener en cuenta que también son las interpretadas por miembros de cofradías a quienes proporcionan una identidad especial en su comunidad.

La finalidad principal de esta recopilación era la de elaborar un gran inventario nacional de canciones, danzas, trajes y costumbres que pasara a los repertorios de los Coros y Danzas formados en las diferentes provincias, quienes a través de los concursos los difundían a nivel nacional e internacional y de esta forma colaboraban en la formación de una identidad española. Interesaba fundamentalmente la pieza en sí misma, que una vez inventariada pasaba a ser "apropiada" para toda la nación, a la que, de alguna forma, servía de "lección". Es, pues patente y consciente el uso político dado por la S.F. a la música, a la que se incluyó en políticas culturales dirigidas a promover los intereses públicos, de educación y estudio pero también a afirmar la hegemonía de sus promotores. En este caso, el valor político otorgado a la música no residía tanto en sí misma - los sonidos y los textos - como en el contexto de su ejecución y puesta en escena, convertido en un acontecimiento múltiple en el que factores muy diversos -emocionales, ideológicos, estéticos...- influyeron en la audición y la percepción. Todo lo cual se refleja en las manifestaciones favorables o contrarias a las actuaciones de los Coros y Danzas, o las distintas reacciones ante la llegada a los pueblos de las instructoras de las cátedras y de educación física de la Sección Femenina o de las Misiones Pedagógicas de la República. En este sentido, la música pudo intensificar el mensaje político apelando a las emociones en aquellas personas que coincidían con él, pero también produjo el efecto contrario en las que no se sentían comprometidas con la ideología que representaban, amortiguando las sensaciones contrarias y anestesiando la conciencia colectiva.

19. Es el caso de las danzas palos, cintas y espadas de Molina de Aragón, Valverde de las Arroyos y Utande o "el pollo", de Maranchón. Entre los paloteos desaparecidos en los últimos años, que también fueron recopilados, figuran los de Albalate de Zorita y Condemios. 